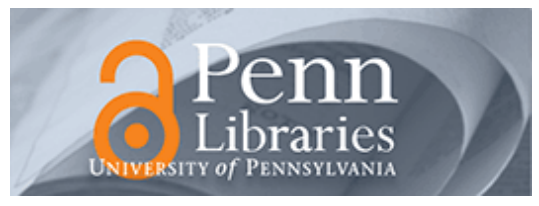

University of Pennsylvania ScholarlyCommons

\title{
Are Liars Ethical? On the Tension between Benevolence and Honesty
}

Emma E. Levine

Maurice E. Schweitzer

University of Pennsylvania

Follow this and additional works at: https://repository.upenn.edu/mgmt_papers

Part of the Business Law, Public Responsibility, and Ethics Commons, Cognition and Perception Commons, Cognitive Psychology Commons, Interpersonal and Small Group Communication Commons, Legal Theory Commons, Management Sciences and Quantitative Methods Commons, and the Social Psychology Commons

\section{Recommended Citation}

Levine, E. E., \& Schweitzer, M. E. (2014). Are Liars Ethical? On the Tension between Benevolence and Honesty. Journal of Experimental Social Psychology, 53 107-117. http://dx.doi.org/10.1016/ j.jesp.2014.03.005

This paper is posted at ScholarlyCommons. https://repository.upenn.edu/mgmt_papers/329

For more information, please contact repository@pobox.upenn.edu. 


\title{
Are Liars Ethical? On the Tension between Benevolence and Honesty
}

\begin{abstract}
We demonstrate that some lies are perceived to be more ethical than honest statements. Across three studies, we find that individuals who tell prosocial lies, lies told with the intention of benefitting others, are perceived to be more moral than individuals who tell the truth. In Study 1, we compare altruistic lies to selfish truths. In Study 2, we introduce a stochastic deception game to disentangle the influence of deception, outcomes, and intentions on perceptions of moral character. In Study 3, we demonstrate that moral judgments of lies are sensitive to the consequences of lying for the deceived party, but insensitive to the consequences of lying for the liar. Both honesty and benevolence are essential components of moral character. We find that when these values conflict, benevolence may be more important than honesty. More broadly, our findings suggest that the moral foundation of care may be more important than the moral foundation of justice.
\end{abstract}

\section{Keywords}

lying, deception, unethical behavior, ethical dilemmas, moral judgment, white lies

\section{Disciplines}

Business Law, Public Responsibility, and Ethics | Cognition and Perception | Cognitive Psychology | Interpersonal and Small Group Communication | Legal Theory | Management Sciences and Quantitative Methods | Social Psychology 
Running Head: Ethics of lying

Are liars ethical?

On the tension between benevolence and honesty

Emma E. Levine $^{\mathrm{a}}$ and Maurice E. Schweitzer ${ }^{\mathrm{a}}$

${ }^{\mathrm{a}}$ The Wharton School

University of Pennsylvania

JMHH, 3730 Walnut Street

University of Pennsylvania

Philadelphia, PA 19104

Cite as: Levine, E. E., \& Schweitzer, M. E. (2014). Are liars ethical? On the tension between benevolence and honesty. Journal of Experimental Social Psychology, 53, 107-117.

Address correspondence to Emma E. Levine, The Wharton School, The University of Pennsylvania, 3730 Walnut St., Philadelphia, PA 19104. Phone: (414) 732 0664. E-mail: emmased@wharton.upenn.edu 


\begin{abstract}
We demonstrate that some lies are perceived to be more ethical than honest statements. Across three studies, we find that individuals who tell prosocial lies, lies told with the intention of benefitting others, are perceived to be more moral than individuals who tell the truth. In Study 1, we compare altruistic lies to selfish truths. In Study 2, we introduce a stochastic deception game to disentangle the influence of deception, outcomes, and intentions on perceptions of moral character. In Study 3, we demonstrate that moral judgments of lies are sensitive to the consequences of lying for the deceived party, but insensitive to the consequences of lying for the liar. Both honesty and benevolence are essential components of moral character. We find that when these values conflict, benevolence may be more important than honesty. More broadly, our findings suggest that the moral foundation of care may be more important than the moral foundation of justice.
\end{abstract}

Word count: 154

Keywords: lying, deception, unethical behavior, ethical dilemmas, moral judgment 
"To me, however, it seems certain that every lie is a sin..." - St. Augustine (circa 420 A.D.) "By a lie, a man annihilates his dignity." - Immanuel Kant (circa 1797) “...deception is unethical." - Chuck Klosterman, The New York Times, "The Ethicist” (2014)

For centuries, philosophers and theologians have characterized lying as unethical (Kant, 1785; for review, see Bok, 1978). Similarly, ethics scholars have argued that honesty is a critical component of moral character (e.g. Wojciszke, 2005; Rosenberg, Nelson, Vivekananthan, 1998) and a fundamental aspect of ethical behavior (e.g. Ruedy, Moore, Gino, \& Schweitzer, 2013).

The conceptualization of lying as immoral, however, is difficult to reconcile with its prevalence. Lying is common in everyday life (DePaulo \& Kashy, 1998; Kashy \& DePaulo, 1996). Not only do people lie to benefit themselves (e.g. lying on one's tax returns), but people also lie to benefit others (e.g. lying about how much one likes a gift) or to serve both selfinterested and prosocial motives. This broader conceptualization of lying to include prosocial or mixed-motive deception has been largely ignored in ethical decision-making research.

In studies of ethical decision-making, scholars have routinely confounded deception with self-serving motives and outcomes. This is true of both theoretical and empirical investigations of deception (e.g., Mazar, Amir, \& Ariely, 2008; Shalvi, Dana, Handgraaf, \& De Dreu, 2011; Shalvi, 2012; Tenbrunsel, 1998; Boles, Croson \& Murninghan, 2000; Shu, Mazar, Gino, Ariely, \& Bazerman, 2012; Ruedy, Moore, Gino, \& Schweitzer, 2013; Mead, Baumeister, Gino, Schweitzer, \& Ariely, 2009; Koning, Steinel, Beest, \& van Dijk, 2011; Steinel \& De Dreu, 2004; Gaspar \& Schweitzer, 2013; Schweitzer, DeChurch, \& Gibson, 2005). For example, ethics scholars who have conflated lying with self-serving motives have investigated behaviors like cheating on one's taxes (e.g. Shu, et al., 2012), inflating self-reported performance (e.g., Mazar 
et al., 2008; Ruedy et al., 2013; Mead, et al., 2009), misreporting a random outcome for financial gain (e.g. Shalvi et al., 2011) and lying to a counterpart to exploit them (Koning, et al., 2011; Steinel \& De Dreu, 2004).

Related research has studied the interpersonal consequences of deception. This work has found that lying harms interpersonal relationships, induces negative affect, provokes revenge, and decreases trust (Tyler, Feldman, \& Reichert, 2006; Boles, Croson \& Murnighan, 2000; Schweitzer \& Croson, 1999; Schweitzer, Hershey, \& Bradlow, 2006; Croson, Boles, \& Murnighan, 2003). All of this research, however, has studied lies that are motivated by selfinterest, such as the desire for reputational or financial gains. As a result of this narrow conceptualization of deception, what we know about the psychology of deception is limited. Quite possibly, our understanding of deception may simply reflect attitudes towards selfish behavior, rather than deception per se.

In contrast to prior research that has assumed that deception is immoral, we demonstrate that lying is often perceived to be moral. In the present research, we disentangle deception from self-interest and explore the moral judgment of different types of lies. Across three studies, we find that lying to help others increases perceptions of moral character.

Our research makes two central contributions to our understanding of deception and moral judgment. First, we challenge the universal presumption that deception is immoral and that honesty is moral. We demonstrate that perceptions of honesty and deception are far more complex than prior work has assumed. This qualifies extant research and illustrates the need to explore a broader set of dishonest behaviors when investigating attitudes towards deception. Second, we explore the conflict between two universal moral foundations: justice and care. Justice is a moral foundation that prioritizes fairness, honesty and moral principles and rules; 
care is a moral foundation that prioritizes the obligation to help and protect other people (Gilligan, 1982; Haidt \& Graham, 2007; Walker \& Hennig, 2004). Prior studies that have focused on violations of either justice or care offer little insight into how individuals resolve dilemmas with competing moral principles. Our investigation has broad practical significance because in many settings, justice and care conflict. Prosocial lies reflect this conflict.

\section{Prosocial lies}

In routine interactions, individuals often face opportunities to tell prosocial lies. We may tell a host that their meatloaf was delicious, a child that we love their artwork, or a colleague that his or her work makes an interesting contribution. Consistent with prior research, we define lies as false statements made with the intention of misleading a target (Depaulo, Kashy, Kirkendol, Wyer, \& Epstein, 1996). We define prosocial lies as false statements made with the intention of misleading and benefitting a target (Levine \& Schweitzer, 2013). We distinguish prosocial lies from altruistic lies and define altruistic lies as a subset of prosocial lies; altruistic lies are false statements that are costly for the liar and are made with the intention of misleading and benefitting a target (Erat \& Gneezy, 2012; Levine \& Schweitzer, 2013).

We also distinguish prosocial lies from white lies. White lies involve small stakes and are "of little moral import" (Bok, 1978: 58). White lies can be either self-serving or prosocial. We define white lies as false statements made with the intention of misleading a target about something trivial. In contrast, prosocial lies are intended to benefit the target and can have small or substantial consequences. For example, parents may tell prosocial lies about their marriage to protect their children (e.g. Barnes, 2013), government authorities may tell prosocial lies to citizens, hoping to protect them (e.g. Bok, 1978), and doctors may tell prosocial lies about the severity of a prognosis to help a patient (e.g. Park, 2011; Palmieri \& Stern, 2009; Iezzoni, Rao, 
DesRoches, Vogeli\& Campbell, 2012). In fact, a recent study found that over 55\% of doctors describe prognoses in a more positive manner than warranted, and over $10 \%$ of doctors explicitly lie to patients (Iezzoni, et al., 2012).

A few studies have explored the frequency of deception in routine communication. This work found that individuals lie in approximately $20 \%$ of their social interactions, and many of these lies are prosocial (DePaulo et al., 1996). Studies have also found that women tell more prosocial lies than men (Erat \& Gneezy, 2012; Dreber \& Johannesson, 2008) and that prosocial lies are most often told to close family members (DePaulo \& Kashy, 1998) and to people who are emotionally invested in the content of the lie (DePaulo \& Bell, 1996). Prosocial lies are often told as a form of politeness (Brown \& Levinson, 1987; Goffman, 1967).

In the present research, we explore moral judgments of prosocial lies. Prosocial lying is an ethically ambivalent act; prosocial lying signals care for others (a positive moral signal), but also disregard for the moral principle of honesty (a negative moral signal). By pitting the signals of care and honesty against each other, we build our understanding of the relationship between ethical conflicts and moral character judgments.

\section{Judging moral character}

To manage and coordinate interpersonal relationships, individuals assess the moral character of those around them (e.g. Reeder, 2009). Research on moral character judgments has largely focused on perceptions of an actor's motives. When individuals observe an unethical act, they can make either personal or situational attributions for the action (e.g. Knobe, 2004; Yuill \& Perner, 1988; Young \& Saxe, 2008). In making these attributions, individuals seek to understand the intentionality of the actor's actions (Alicke, 1992; Darley \& Pittman, 2003; Pizarro, Uhlmann, \& Bloom, 2003). Individuals make inferences about an actor's intentionality by using 
characteristics of the decision-making process as information (see Ditto, Pizzaro, \& Tannenbaum, 2009 for review). For example, individuals who make quick moral decisions are perceived to be more moral than individuals who take their time to arrive at a moral decision, because a quick decision signals that an actor was certain about her judgment (Critcher, Inbar, \& Pizarro, 2013).

Recent research has expanded our understanding of the different signals, such as decision speed, that influence perceptions of ethicality. However, there is still much to learn about the traits and values that really matter for judgments of moral character (e.g. Leach, Ellemers, \& Barreto, 2007; Brambilla, Sacchi, Rusconi, Cherubini, \& Yzerbyt, 2012).

Scholars argue that justice and care are two key components of moral character (Walker \& Hennig, 2004; Aquino \& Reed, 2002; Lapsley \& Lasky, 2001). Justice reflects respect for overarching moral rules, such as "do not lie.” Care reflects the obligation to help and protect others (Gilligan, 1982; Haidt \& Graham, 2007; Walker \& Hennig, 2004). Though many scholars identify these two components as the core foundations of moral reasoning (Kohlberg, 1969; Gilligan, 1982), others have expanded the set of moral foundations to include Purity, Authority, and In-group Loyalty (Haidt \& Graham, 2007, Graham, Haidt, \& Nosek, 2009). In our investigation, we focus on justice and care.

Extant ethics research has primarily studied acts that violate either justice or care (e.g. Tannenbaum, Uhlmann, \& Diermeier, 2011). In these cases, the ethical choice is often clear. However, when justice and care conflict, the ethical choice is unclear. Surprisingly, little work has examined the moral judgment of competing moral principles (for an exception, see Uhlmann \& Zhu, 2013). In the present research, we explore the tension between justice and care by 
studying prosocial lies. Prosocial lies represent a justice violation (e.g. "Never tell a lie") that signals care.

The majority of research in moral psychology argues that, at its core, "morality is about protecting individuals" (Haidt \& Graham, 2007: 100). Caring for others is fundamental to the human experience and humans are hardwired to detect harm to others (de Waal, 2008; Graham, et al., 2011; Craig, 2009). For example, individuals often construe immoral acts as causing harm, even when no objective harm has been done (Gray, Schein, \& Ward, 2014). Some scholars have even suggested that moral rules of justice evolved to protect people from harm (Gray, Young, \& Waytz, 2012). That is, the reason we value justice may have more to do with its role in protecting individuals, than our preference for formal rules (Turiel, 1983; Turiel, Hildebrandt, \& Wainryb, 1991; Rai \& Fiske, 2011).

Consistent with this notion, we postulate that when justice causes harm to individuals (i.e., when justice and care conflict), concerns for care will supersede concerns for justice. Consequently, we expect observers to judge individuals who tell lies that help others to be more moral than individuals who are honest, but harm others.

\section{The present research}

Across three studies, we examine moral judgments of individuals who tell prosocial lies. In Study 1, we find that altruistic lies are perceived to be moral. We compare altruistic lies to selfish truths and find that individuals who lie to help others are perceived to be more moral than individuals who are honest. In Study 2, we disentangle deception, outcomes, and intentions. We find that intentions matter profoundly, but that the outcomes associated with deception do not influence judgments of morality. 
In Study 3, we extend our investigation by disentangling the consequences of lying for the liar and the consequences of lying for the deceived party. We find that lies that neither help nor harm others are perceived to be immoral, but lies that help others, regardless of their cost to the liar, are perceived to be moral. Taken together, our studies demonstrate that the perceived ethicality of deception is labile. Intentions matter, and in at least some domains, caring for others is perceived to be more diagnostic of moral character than honesty.

\section{Study 1}

In Study 1, we examine moral judgments of altruistic lies and selfish truths. In our first study, participants judged an individual's actions in a deception game. In this experiment, lying benefited the deceived party at a cost to the deceiver. In this study, we find that altruistic lies are perceived to be moral.

\section{Method}

Participants. We recruited 215 participants from a city in the northeastern United States to participate in a study in exchange for a $\$ 10$ show-up fee.

Procedure and Materials. We randomly assigned participants to one of two conditions in a between-subjects design. Participants observed and then judged an individual who either told an altruistic lie or was selfishly honest.

We told participants that they would observe the decision another participant had made in a prior exercise, called “The Number Game.” The prior participant's decision in The Number Game served as our manipulation of lying.

The Number Game. We modified the deception game (Erat \& Gneezy; 2012; Cohen, Gunia, Kim-Jun, \& Murnighan, 2009; Gneezy; 2005) to create The Number Game. 
In The Number Game, two individuals were paired and randomly assigned to the role of either Sender or Receiver. The payoffs for each pair of participants were determined by the outcome of a random number generator and the choices made by the Sender and the Receiver. We refer to the individual who sent the message (who either lied or was honest) as "the Sender" throughout our studies. We refer to the Sender's partner (the individual who received the message) as "the Receiver." In our studies, participants observed and judged the behavior of one Sender in The Number Game.

The rules of The Number Game were as follows:

1. Senders were told a number supposedly generated by a random number generator $(1,2,3,4$, or 5$)$. In our study, the number was always 4 .

2. The Sender then had to report the outcome of the random number generator to his/her partner, the Receiver. The Sender could send one of five possible messages to the Receiver. The message could read, "The number picked was [1, $2,3,4$, or 5]."

$\circ$ The Sender knew that the number the Receiver chose $(1,2,3,4$, or 5) determined the payment in the experiment. The Sender also knew that the only information the Receiver would have was the message from the Sender and that most Receivers chose the number indicated in the Sender's message.

○ The Sender knew there were two possible payment options, A and B. If the Receiver chose the correct number, the Sender and the Receiver would be paid according to Option A. Otherwise, the Sender and the Receiver would be paid according to Option B. 
3. In Study 1, the payoffs for Option A were $\$ 2$ for the Sender and $\$ 0$ for the Receiver. The payoffs for Option B were $\$ 1.75$ for the Sender and $\$ 1$ for the Receiver.

4. After receiving the Sender's message, the Receiver chose a number: 1, 2, 3, 4 or 5. The Receiver knew that his/her choice determined the payment in the experiment, but the Receiver did not know the payoffs associated with the choices. The Sender's message was the only piece of information the Receiver had.

Therefore, Senders faced the following options:

A. $\quad$ Send an honest message, e.g. "The number picked was 4." Honesty was most likely to lead to an outcome that was costly for the Receiver, and beneficial for Sender (i.e. selfish).

B. $\quad$ Send a dishonest message, e.g. "The number picked was [1, 2, 3, or 5]." Lying was most likely to lead to an outcome was beneficial for the Receiver, and was costly to the Sender (i.e. altruistic).

Design of the present study. Participants in our study learned the rules of The Number Game and had to pass a comprehension check to continue with the study.

Participants who passed the comprehension check learned about the behavior of a prior Sender. Specifically, participants observed a Sender who either sent an honest, but selfish message (Option A) or sent a deceptive, but altruistic message (Option B). We provide a summary of the payoffs associated with each choice in Table 1.

Dependent variables. After learning about the Sender's choice and the outcome of The Number Game, participants rated the Sender. We used seven-point Likert scales for all ratings. 
Participants rated whether the Sender was ethical, moral, and a good person, and the extent to which the Sender's decision was ethical and moral $(\alpha=.93)$. These items were anchored at $1=$ "Not at all" and $7=$ "Extremely."

Participants also rated the benevolence of the Sender using two items: "This person is kind" and "This person has good intentions," $(r(196)=.83)$, and the honesty of the Sender using two items: "This person is honest" and "This person tells the truth," $(r(196)=.96)$. These items were anchored at $1=$ "Strongly disagree" and $7=$ "Strongly agree."

We also asked two multiple-choice recall questions to ensure participants had paid attention to our manipulations: "What message did the Sender send to his or her Receiver?" and "What was the actual number chosen by the random number generator?"1

After participants submitted their responses, we collected demographic information and asked participants what they thought the purpose of the study was. We ran this study for the length of one laboratory session and we report all data exclusions and manipulations (Simmons, Nelson \& Simonsohn, 2011).

\section{Results}

We report results from 196 participants $\left(62.2 \%\right.$ female; $M_{\text {age }}=20.4$ years, $\left.S D=2.38\right)$ who passed the comprehension check and completed the entire study; 19 participants failed the comprehension check at the start of the experiment and were automatically eliminated from the study. We present the means and standard deviations of each of our scales, as well as the interscale correlation matrix in Table 2. An exploratory factor analysis (Varimax rotation) yielded

\footnotetext{
${ }^{1}$ A total of $94.9 \%$ of participants correctly answered both recall questions. We report analyses for all participants who completed the entire study, but none of our findings change when we restrict our sample to only those who correctly answered the recall questions.
} 
two factors that accounted for $74.06 \%$ of the variance. The first factor (eigenvalue $=5.32$ ) consisted of the five morality items and the two benevolence items (loadings $\geq|.79|$ ), and the second factor (eigenvalue $=1.77)$ consisted of the two honesty items (loadings $\geq|.86|)$.

Although perceived benevolence and moral character are closely linked (e.g. Haidt \& Graham, 2007) and loaded onto one factor, benevolence is theoretically distinct from morality (e.g. Haidt \& Graham, 2007; Walker \& Hennig, 2004; Leach et al., 2007; Brambilla et al., 2012). Consequently, we present analyses of benevolence and moral character separately. However, our results follow the same pattern if we combine these items into one construct. This was the case across all three of our studies. ${ }^{2}$

We conducted a one-way ANOVA to examine the effect of altruistic lying on perceived benevolence, honesty, and moral character. Participants judged altruistic liars to be more moral $(M=5.03, S D=1.13)$ than selfish truth-tellers $(M=4.30, S D=1.09), F(1,194)=21.52, p<$ $.001, \eta_{p}^{2}=.100$ (see Figure 1). Participants also judged altruistic liars to be more benevolent $(M=$ 5.36, $S D=1.29)$ than selfish truth-tellers $(M=3.98, S D=1.32), F(1,194)=53.90, p<.001, \eta_{p}^{2}$ $=.217$. However, altruistic liars were judged to be less honest $(M=3.50, S D=1.19)$ than selfish truth-tellers $(M=5.06, S D=1.40), F(1,194)=69.98, p<.001, \eta_{p}^{2}=.265$.

Figure 1 here

\footnotetext{
${ }^{2}$ We thank an anonymous reviewer for his/her recommendation to explore our factor structure.
} 


\section{Discussion}

In contrast to prior research that assumes that dishonesty undermines moral character, we find that, at least in some cases, lying increases moral character. In particular, we find that individuals perceive those who tell altruistic lies to be more moral than those who tell selfish truths. Study 1 suggests that when benevolence and honesty conflict, benevolence may be more important than honesty.

\section{Study 2}

In Study 2, we extend our investigation of deception and judgments of moral character. In this study, we use a deception game similar to the game we used in Study 1. In Study 2, however, we independently manipulate intentions, outcomes, and deception. This design enables us to measure the effect of deception, controlling for (selfish and altruistic) intentions. That is, in this study, we disentangle the effects of honesty and benevolence.

In Study 2, we also introduce informational uncertainty. In many practical contexts, individuals tell lies, but are uncertain of the consequences. For example, we may tell a colleague that his presentation was great with the intention of helping by boosting his confidence. This lie, however, may actually lead to an unintended outcome such as overconfidence and less preparation. We disentangle intentions from outcomes to investigate perceptions of lies that are told with good intentions but lead to negative outcomes.

\section{Method}

Participants. We recruited 237 participants from a city in the northeastern United States to participate in a study in exchange for a $\$ 10$ show-up fee.

Procedure and Materials. As in Study 1, participants observed the decisions an individual made in an exercise called "The Number Game." We randomly assigned participants 
to one of eight experimental conditions in a 2(Intentions: Altruistic vs. Selfish) x 2(Lying: Lie vs. Truth) x 2(Outcome: Altruistic vs. Selfish) between-subjects design. Specifically, participants observed a Sender who either lied or sent an honest message, whose intentions were either selfish or altruistic, and whose choice ultimately led to an outcome that was either altruistic or selfish.

The Number Game. The Number Game in Study 2 was similar to the game we used in Study 1, with two notable changes. First, we introduced a stochastic element to the game to disentangle the effects of outcomes and intentions. Specifically, Senders in this game knew that the message that s/he selected was only delivered to the Receiver $75 \%$ of the time. Senders learned that $25 \%$ of the time, the computer overrode their decision and delivered the opposite message to the Receiver. That is, whether or not the Receiver received a truthful or deceptive message was probabilistically determined. In the actual experiment, the computer overrode the confederate Sender's decision (i.e. intentions) half of the time so that our cells were evenly balanced.

Second, Senders in this experiment played The Number Game with one of two possible payment structures. These payment structures enabled us to manipulate whether deception or honesty was associated with selfish or altruistic intentions. We provide a summary of the payoffs associated with each choice in Table 1.

The first payment structure was identical to the one we used in Study 1. This payment structure represented the choice between selfish honesty (Option A) and altruistic lying (Option B). The second payment structure represents the choice between altruistic honesty and selfish lying. In the second payment structure, Senders learned that they would receive $\$ 1.75$ and the Receiver would receive $\$ 1$ if the Receiver chose the correct number (Option A). Otherwise, the 
Sender would receive $\$ 2$ and the Receiver would receive $\$ 0$ (Option B). (As in Study 1, the correct number was always 4).

Therefore, Senders with the second payment structure faced the following options:

A. Send an honest message, e.g. "The number picked was 4."

Honesty was most likely to lead to an outcome that benefitted the Receiver and was costly to the Sender (i.e. altruistic).

B. Send a dishonest message, e.g. "The number picked was [1, 2, 3, or 5]."

Lying was most likely to lead to an outcome that was costly to the Receiver and benefitted the Sender (i.e. selfish).

Design of the present study. Participants in our study learned the rules of The Number Game and had to pass a comprehension check to continue with the study.

Participants who passed the comprehension check then learned about the choice the Sender made in The Number Game. Participants observed a Sender who either lied or sent an honest message, who's choice was either intended to be altruistic or selfish, and who's choice led to an outcome (which was probabilistically determined) that was either altruistic or selfish.

For example, in the $\{$ Lying, Altruistic Intentions, Selfish Outcomes $\}$ condition, participants learned the following: the Sender sent a dishonest message to the Receiver; the Sender intended to help the Receiver earn an extra dollar (at a $\$ 0.25$ cost to the Sender); the computer overrode the Sender's decision and the Receiver actually received the honest message. Consequently, the Receiver chose the correct number and earned \$0 and the Sender earned \$2. This selfish outcome, however, was not the Sender's intention. 
Dependent variables. After learning about the Sender's choice and the outcome of The Number Game, participants rated the Sender. We collected the same measures in this study as those we used in Study $1(\alpha=.95 ; r$ 's $>.86)$.

We also asked three multiple-choice recall questions to ensure participants had paid attention to our manipulations: "What message did the Sender send to his or her Receiver?", "What message did the Receiver receive?" and "What was the actual number chosen by the random number generator?"3

After participants submitted their responses, we collected demographic information and asked participants what they thought the purpose of the study was. We ran this study for the length of one laboratory session and we report additional measures we collected in this study in the online supplemental materials.

\section{Results}

We report results from 211 participants $\left(63.5 \%\right.$ female; $\mathrm{M}_{\mathrm{age}}=24$ years, $\left.\mathrm{SD}=7.21\right)$ who passed the comprehension check and completed the entire study; 26 participants failed the comprehension check and were automatically eliminated from the study. We present the means and standard deviations of each scale, as well as the inter-scale correlation matrix in Table 2. An exploratory factor analysis (Varimax rotation) yielded one factor that accounted for $77.10 \%$ of the variance (eigenvalue $=6.94$ ). Consistent with Study 1, we report the results of our manipulations on moral character, benevolence, and honesty separately. However, the pattern of results is the same when we combine all of our items into one measure of moral character.

\footnotetext{
${ }^{3}$ A total of $75.8 \%$ of participants correctly answered all three recall questions. We report analyses for all participants who completed the entire study, but none of our findings change when we restrict our sample to only those who correctly answered all of the recall questions.
} 
We conducted a three-way ANOVA on our dependent variables, using Intentions, Lying, and Outcomes as factors. We found no main effects or interaction effects of Outcomes, and consequently collapsed across this factor in subsequent analyses. That is, outcomes did not influence moral judgments in this study, and our findings are unchanged when we include Outcomes as a factor. In other words, whether or not lying actually led to its intended consequence did not influence perceptions of moral character.

Moral character. A two-way ANOVA revealed a main effect of Lying, $F(1,207)=$ $34.22, p<.001, \eta_{p}^{2}=.142$, and a main effect of Intentions, $F(1,207)=77.26, p<.001, \eta_{p}^{2}=$ .272 , on perceptions of the Sender's moral character. Specifically, participants believed that the Sender was more moral when $\mathrm{s} / \mathrm{he}$ was honest $(M=4.98, S D=1.34)$ than when $\mathrm{s} / \mathrm{he}$ lied $(M=$ 3.97, $S D=1.46)$ and when $\mathrm{s} /$ he had altruistic intentions $(M=5.21, S D=1.26)$ than when $\mathrm{s} / \mathrm{he}$ had selfish intentions $(M=3.71, S D=1.30)$. We did not find a significant Lying $\mathrm{x}$ Intentions interaction, $F(1,207)=1.10, p=.295, \eta_{p}^{2}=.005$.

In order to compare altruistic lying and selfish honesty, we conducted a series of planned contrasts. Consistent with Study 1, a contrast between the Altruistic Lie and the Selfish Truth conditions revealed that Senders who told altruistic lies were judged to be more moral than Senders who told selfish truths $(M=4.80, S D=1.30$ vs. $M=4.31, S D=1.27), t(100)=2.04, p=$ $.043, d=.38$. We depict these results in Figure 2. Notably, altruistic lies and altruistic truths were rated as moral, (significantly above the midpoint on the scale, $p<.001$ ). Only selfish lies were rated as immoral (significantly below the midpoint of the scale, $p<.001$ ).

Figure 2 here 
Benevolence. A two-way ANOVA revealed a main effect of Lying, $F(1,207)=29.52, p$ $<.001, \eta_{p}^{2}=.125$, and a main effect of Intentions, $F(1,207)=92.91, p<.001, \eta_{p}^{2}=.310$, on perceptions of the Sender's benevolence. Specifically, participants believed that the Sender was more benevolent when $\mathrm{s} / \mathrm{he}$ was honest $(M=4.92, S D=1.44)$ than when $\mathrm{s} /$ he lied $(M=3.91, S D$ $=1.71)$ and when $\mathrm{s} /$ he had altruistic intentions $(M=5.32, S D=1.38)$ than when $\mathrm{s} / \mathrm{he}$ had selfish intentions $(M=3.54, S D=1.42)$. We also found a marginally significant Lying x Intentions interaction, $F(1,207)=2.95, p=.087, \eta_{p}^{2}=.014$, such that selfish intentions, relative to altruistic intentions, were perceived to be less benevolent when they were associated with lying $\left(M_{\text {altruistic }}=\right.$ 4.97, $S D_{\text {altruistic }}=1.58$ vs. $\left.M_{\text {selfish }}=2.91, S D_{\text {selfish }}=1.14\right), t(104)=5.61, p<.001, d=1.56$, than when they were associated with honesty $\left(M_{\text {altruistic }}=5.64, S D_{\text {altruistic }}=1.10\right.$ vs. $M_{\text {selfish }}=4.21, S D$ selfish $=1.40), t(105)=2.64, p<.01, d=1.14$. That is, selfishness is perceived to be less benevolent - or more malevolent - when it is associated with deception than when it is associated with honesty.

Planned contrasts between the Selfish Truth and the Altruistic Lie conditions revealed that participants perceived the Sender to be more benevolent when s/he told an altruistic lie $(M=$ 4.97, $S D=1.58)$ than when s/he told a selfish truth $(M=4.21, S D=1.40), t(100)=2.91, p<.01$, $d=.51$.

Honesty. A two-way ANOVA also revealed a main effect of Lying, $F(1,207)=167.35, p$ $<.001, \eta_{p}^{2}=.447$, and a main effect of Intentions, $F(1,207)=35.46, p<.001, \eta_{p}^{2}=.146$, on perceptions of the Sender's honesty. Specifically, participants believed that the Sender was more honest when $\mathrm{s} / \mathrm{he}$ told the truth $(M=5.53, S D=1.31)$ than when $\mathrm{s} / \mathrm{he}$ lied $(M=3.14, S D=1.54)$ 
and when s/he had altruistic intentions $(M=4.93, S D=1.61)$ than when s/he had selfish intentions $(M=3.75, S D=1.92)$.

We also found a significant Lying $\mathrm{x}$ Intentions interaction, $F(1,207)=5.18, p=.024, \eta_{p}^{2}$ $=.024$, such that the same lie was perceived to be less honest, relative to truth-telling, when it was associated with selfish intentions $\left(M_{\text {truth }}=5.18, S D_{\text {truth }}=1.47\right.$ vs. $\left.M_{\text {lie }}=2.42, S D_{\text {lie }}=1.20\right)$, $t(103)=10.68, p<.001, d=2.06$, compared to altruistic intentions,$\left(M_{\text {truth }}=5.85, S D_{\text {truth }}=1.07\right.$ vs. $\left.M_{\mathrm{lie}}=3.91, S D_{\mathrm{lie}}=1.51\right), t(106)=7.59, p<.001, d=1.48$. In other words, an otherwise identical lie is perceived to be less dishonest when it is associated with altruism.

Planned contrasts between the Selfish Truth and the Altruistic Lie conditions revealed that participants perceived the Sender to be less honest when the Sender told an altruistic lie ( $M$ $=3.91, S D=1.51)$ than when the Sender told a selfish truth $(M=5.18, S D=1.47), t(100)=4.83$, $p<.01, d=.85$.

\section{Discussion}

In Study 2, we manipulated intentions, deception, and outcomes independently and found that intentions influenced judgments of moral character more than deception or outcomes. In this study, participants judged Senders who told altruistic lies to be more moral than Senders who told selfish truths. In this study, the only decisions participants judged to be immoral were selfish lies.

We also found that judgments of honesty influenced judgments of benevolence and judgments of benevolence influenced judgments of honesty. Controlling for deceptive behavior, altruistic intentions signaled honest character, and controlling for intentions, honesty signaled benevolent character. That is, a single moral behavior triggered a halo of unrelated moral trait 
attributions. However, as expected, judgments of benevolence were more sensitive to intentions and judgments of honesty were more sensitive to deception.

Importantly, we also found that outcomes, when disentangled from deception and intentions, had no effect on moral judgments of deception. These findings offer new insight into the psychology of deception. The consequences of deception, and unethical behavior generally, are uncertain. Interestingly, we find that whether or not (dis)honesty actually helped or hurt did not influence judgments of moral character.

\section{Study 3}

In Studies 1 and 2, we examined altruistic lies. Altruistic lies are costly for the liar and beneficial for the target. In Study 3, we manipulate the consequences of deception for the Sender and the Receiver independently. This enables us to disentangle attributions of benevolence from attributions of altruism, and to contrast altruistic lies with non-altruistic prosocial lies. In this design, we also include a control condition that directly examines perceptions of lying, free of consequences for the liar and the deceived party.

\section{Method}

Participants. We recruited 300 adults to participate in an online survey via Amazon's Mechanical Turk.

Procedure and Materials. As in Studies 1 and 2, participants learned about the decisions an individual made in an exercise, called "The Number Game." In Study 3, we randomly assigned participants to one of eight cells in a 2(Lying: Lie vs. Truth) $\mathrm{x} 2$ (Consequences for the Sender: None vs. Cost) x 2(Consequences for the Receiver: None vs. Benefit) between-subjects design. That is, participants learned the following about a Sender: the Sender either lied or was 
honest; lying was either costly for the Sender or had no effect on the Sender; and lying either benefited the Receiver or had no effect on the Receiver.

The Number Game. The Number Game in Study 3 was similar to the game we used in Study 1. Participants learned about a Sender who either accurately reported or lied about the outcome of a random number generator. We manipulated the payoffs associated with honesty and lying by manipulating the payments associated with decisions in The Number Game.

In Study 3, participants viewed one of four possible payment structures. These payment structures varied the payoffs associated with lying for the Sender and the Receiver. These payment structures, depicted in Table 1, operationalized one of four types of lies:

1. Control Lie: Lying, relative to honesty, had no effect on the Sender or the Receiver.

2. Self-sacrificial Lie: Lying, relative to honesty, hurt the Sender and had no effect on the Receiver.

3. Prosocial Lie: Lying, relative to honesty, had no effect on the Sender and benefited the Receiver.

4. Altruistic Lie: Lying, relative to honesty, hurt the Sender and benefited the Receiver. Participants learned about a Sender who faced the opportunity to tell one of the four types of lies described above. For example, Senders in the Prosocial Lie conditions had the opportunity to send a dishonest message to the Receiver, which would have no effect on the Sender but would benefit the Receiver. In each condition, participants learned that the Sender either lied or told the truth. Honesty was associated with the same payoffs in all conditions ( $\$ 2$ for the Sender, $\$ 0$ for the Receiver). 
As in Studies 1 and 2, participants had to pass a comprehension check to ensure that they understood The Number Game before they could continue with the experiment. Participants who failed the comprehension check were automatically removed from the study.

Dependent variables. After learning about the Sender's choice and passing the comprehension check, participants rated the Sender. We developed new scales in Study 3 to better distinguish judgments of moral character from judgments of benevolence and honesty.

Moral character. We measured moral character using six items $(\alpha=.96)$ we adapted from Uhlmann, Zhu, \& Tannenbaum (2013). Specifically, we asked participants whether the Sender had "good moral character" ( 1 = "Extremely immoral character", 7 = "Extremely moral character"), was "an ethical person" ( 1 = "Extremely unethical person," 7 = "Extremely ethical person"), was "a morally good person" ( 1 = "Extremely morally bad person," 7 = "Extremely morally good person"), "will behave morally in the future" (1= "Extremely likely to behave immorally", 7 = "Extremely likely to behave morally"), "made the morally right decision" $(1=$ "Extremely immoral decision" 7 = "Extremely moral decision"), and "made the ethical decision" (1 = "Extremely unethical decision", 7 = "Extremely ethical decision.").

Benevolence. Participants rated the Sender's benevolence using four items $(\alpha=.89)$ : This person is [benevolent, empathic, caring, selfish (reverse-scored)]. These items were anchored at $1=$ "Strongly disagree" and $7=$ "Strongly agree." We adapted this scale from Uhlmann et al.'s (2013) perceived empathy scale, but we included additional items to measure benevolence rather than general empathy (e.g. selfish, benevolent).

Honesty. Participants rated the honesty of the Sender using three items $(\alpha=.91)$ : This person [is honest, tells the truth, is deceptive (reverse-scored)]; $1=$ "Strongly disagree" and $7=$ "Strongly agree." 
As in Study 1, we also asked two multiple-choice recall questions to ensure participants had paid attention to our manipulations: "What message did the Sender send to his or her Receiver?" and "What was the actual number chosen by the random number generator?"4

After participants submitted their responses, we collected demographic information and asked participants what they thought the purpose of the study was. We determined our sample size in advance and we report all data exclusions and manipulations.

\section{Results}

We report results from 269 participants $\left(45.6 \%\right.$ female; $\mathrm{M}_{\mathrm{age}}=32$ years, $\left.\mathrm{SD}=11.03\right)$ who passed the comprehension check and completed the entire study; 31 participants failed the comprehension check and were automatically eliminated from the study. We present the means and standard deviations of each scale, as well as the inter-scale correlation matrix in Table 2. Although we devised new scales to measure moral character and benevolence, these constructs remained closely related and loaded together on one factor (Exploratory factor analysis, Varimax rotation, loadings $\geq|.65|$ ). Consistent with Studies 1 and 2, we report the results of our manipulations on moral character and benevolence separately, but our findings remain the same when we combine moral character and benevolence into one scale.

We conducted a three-way ANOVA on our dependent variables, using Lying, Consequences for the Sender, and Consequences for the Receiver as factors. We found no main effects or interaction effects of Consequences for the Sender. That is, whether or not lying was costly for the Sender did not influence judgments of the Sender's moral character, benevolence,

\footnotetext{
${ }^{4}$ A total of $87.0 \%$ of participants correctly answered both recall questions. We report analyses for all participants who completed the entire study, but none of our findings change when we restrict our sample to only those who correctly answered the recall questions.
} 
or honesty. Notably, prosocial lies were not judged differently than were altruistic lies. We collapse across Consequences for the Sender in our subsequent analyses, but our findings are unchanged when we include Consequences for the Sender as a factor.

Moral character. We find no main effects of Lying, $F(1,265)=.02, p=.887, \eta_{p}^{2}=.000$, or Consequences for the Receiver, $F(1,265)=2.70, p=.100, \eta_{p}^{2}=.010$, on perceptions of moral character. Importantly, we did find a significant Lying x Consequences for the Receiver interaction, $F(1,265)=41.20, p<.001, \eta_{p}^{2}=.135$. When lying helped the Receiver, the Sender was judged to be more moral when $\mathrm{s} / \mathrm{he}$ lied $(M=4.88, S D=1.36)$ than when $\mathrm{s} / \mathrm{he}$ told the truth $(M=3.90, S D=1.37), t(132)=4.41, p<.001, d=1.01$. Conversely, when lying had no effect on the Receiver, the Sender was judged to be less moral when s/he lied $(M=3.62, S D=1.25)$ than when $\mathrm{s} /$ he told the truth $(M=4.64, S D=1.10), t(135)=4.66, p<.001, d=.87$. Consistent with our findings in Studies 1 and 2, prosocial lying increased perceptions of moral character. Lies that neither helped nor harmed the Receiver, however, decreased perceptions of the Sender's moral character.

Benevolence. A two-way ANOVA revealed main effects of Lying, $F(1,265)=3.76, p=$ $.053, \eta_{p}^{2}=.014$, and Consequences for the Receiver, $F(1,265)=5.61, p=.020, \eta_{p}^{2}=.021$, on perceived benevolence. Specifically, participants believed that the Sender was more benevolent when $\mathrm{s} / \mathrm{he}$ lied $(M=4.09, S D=1.49)$ than when $\mathrm{s} / \mathrm{he}$ was honest $(M=3.81, S D=1.12)$ and when lying helped the Receiver $(M=4.12, S D=1.54)$ than when it had no effect Receiver $(M=3.78$, $S D=1.04)$

However, these effects were qualified by a significant Lying x Consequences for the Receiver interaction, $F(1,265)=45.98, p<.001, \eta_{p}^{2}=.148$. When lying helped the Receiver, the 
Sender was judged to be more benevolent when s/he lied $(M=4.76, S D=1.50)$ than when $\mathrm{s} / \mathrm{he}$ told the truth $(M=3.48, S D=1.30), t(132)=6.13, p<.001, d=.91$. Conversely, when lying did not help the Receiver, the Sender was judged to be less benevolent when s/he lied $(M=3.41, S D$ $=1.13)$ than when $\mathrm{s} /$ he told the truth $(M=4.13, S D=0.79), t(135)=3.44, p<.001, d=.74$. This interaction demonstrates that the main effect of lying on benevolence is driven by judgments of prosocial lies.

Honesty. A two-way ANOVA revealed a significant effect of Lying, $F(1,265)=77.76, p$ $<.001, \eta_{p}^{2}=.227$, on perceived honesty. Participants rated the Sender as less honest when s/he lied $(M=3.41, S D=1.57)$ than when $\mathrm{s} / \mathrm{he}$ told the truth $(M=4.97, S D=1.39)$. We find no effect of Consequences for the Receiver on perceived honesty, $F(1,258)=1.19, p=.276, \eta_{p}^{2}=.004$. The Sender was judged to be similarly honest when lying helped the Receiver $(M=4.28, S D=$ $1.51)$ and when lying had no effect on the Receiver $(M=4.11, S D=1.81)$.

We do find a significant Lying $\times$ Consequences for the Receiver interaction, $F(1,265)=$ 13.11, $p<.001, \eta_{p}^{2}=.047$. Consistent with our findings in Study 2, the difference in perceived honesty between a truth and a lie was greater when lying had no effect on the Receiver, $\left(M_{\text {truth }}=\right.$ $5.19, S D_{\text {truth }}=1.31$ vs. $\left.M_{\text {lie }}=2.99, S D_{\text {lie }}=1.57\right), t(135)=8.84, p<.001, d=1.52$, than when lying helped the Receiver $\left(M_{\text {truth }}=4.74, S D_{\text {truth }}=1.43\right.$ vs. $\left.M_{\text {lie }}=3.83, S D_{\text {lie }}=1.46\right), t(132)=$ $3.65, p<.001, d=.63$. That is, deception was perceived to be more honest when it helped another person.

Judgments of different types of lies. Although Consequences for the Sender had no effect on moral judgments, we sought to better understand perceptions of lies with respect to our control condition. We conducted planned contrasts for each type of lie and we depict these 
results in Figures 3-5. We summarize perceptions of moral character for each type of lie below and in Table 3.

In our control condition, lying was inconsequential. That is, deception and honesty resulted in the same payoffs. In this condition, participants rated the Sender as significantly less moral when s/he lied $(M=3.58, S D=1.30)$ than when s/he told the truth $(M=4.52, S D=1.08)$, $t(67)=3.03, p<.01, d=.79$. This contrast documents an aversion to lying.

We find the same pattern of results for self-sacrificial lies: Participants rated the Sender as significantly less moral when s/he told a self-sacrificial lie $(M=3.68, S D=1.20)$ than when s/he told the truth $(M=4.75, S D=1.12), t(67)=3.44, p=.001, d=.92$. We find no difference between ratings of self-sacrificial lies and inconsequential lies.

We find the opposite pattern of results for prosocial and altruistic lies. Participants rated the Sender as significantly more moral when s/he told a prosocial lie $(M=5.03, S D=1.32)$ than when s/he told the truth $(M=3.87, S D=1.45), t(62)=3.58, p<.001, d=.84$. Similarly, participants rated the Sender as significantly more moral when s/he told an altruistic lie $(M=$ 4.75, $S D=1.40)$ than when s/he told the truth $(M=3.93, S D=1.31), t(69)=2.69, p<.01, d=$ .60. We find no difference between ratings of prosocial and altruistic lies.

Prosocial lies and altruistic lies were both rated to be more moral than lies that had no consequences $(t \mathrm{~s}>3.92, p \mathrm{~s}<.01, d \mathrm{~s}>.86)$. Truth-telling was also rated to be more moral in the control condition than truth-telling in the altruistic lie condition $(t=2.04, p=.042, d=.49)$ and marginally more moral than truth-telling in the prosocial lie condition $(t=1.87, p=.063, d=$ $.51)$, even though the payoffs for truth-telling were identical across these conditions. Taken 
together, our results suggest that having the opportunity to lie to help another party causes lying to appear to be more moral and causes honesty to appear to be less moral.

\section{Figures 3-5, Table 3}

\section{Discussion}

In Study 3, we find that individuals who lie to help others, regardless of whether or not the lie is costly for them, are perceived to be more moral than individuals who are honest. Consistent with our findings in Studies 1 and 2, prosocial motives influenced perceptions of moral character more than deception did.

In addition, we find evidence of a direct distaste for lying. Individuals who told lies that had no consequences for either themselves (the liars) or the deceived party were perceived to be less moral than individuals who were honest. Consistent with Study 2, this result suggests that perceptions of deception are not solely determined by the consequences and intentions associated with lying. To our knowledge, this is the first study to examine moral judgments of deception, independent of its consequences.

\section{General discussion}

Because extant research has conflated deception with self-serving motives and outcomes, our understanding of deception is limited. We know little about how common forms of deception, and conflicts between honesty and benevolence broadly, influence judgment and behavior.

Across three studies, we explore moral judgments of prosocial lies. In Study 1, we find that altruistic lies are perceived to be more moral than selfish truths. In Study 2, we 
independently manipulate deception, prosocial intentions, and prosocial outcomes. We find that outcomes did not influence judgments of moral character, but, consistent with prior work, intentions mattered profoundly (e.g. Alicke, 1992; Ames \& Fiske, 2013). Although deception also had an effect on moral character, we find that the effect of intentions was larger than that of deception. Consequently, individuals with altruistic intentions are perceived to be more moral, more benevolent, and more honest, even when they lie.

In our third study, we examine different types of lies. We find that perceptions of prosocial lies do not depend on self-sacrifice; altruistic lies and prosocial lies both increase perceptions of moral character. We also find evidence for a direct aversion to deception; lies that had no consequences for the liar or the deceived party were perceived to be immoral.

Theoretically, our findings make several contributions. First, we demonstrate the importance of a broader conceptualization of deception. Whereas prior studies of ethical decision-making and moral character have conflated deception with selfishness, we distinguish self-serving deception from altruistic, prosocial, and inconsequential deception. We find that individuals who tell lies that help others are perceived to be moral.

Second, our investigation expands the study of ethical decision making to conflicts between honesty and benevolence. Prior work has studied violations of either honesty or benevolence in isolation, or acts that violate both honesty and benevolence at the same time. To our knowledge, our work is the first to examine character judgments when these values conflict. In our studies, benevolence was more closely related to moral character than honesty. Although we cannot conclude that the principle of benevolence is always more important than honesty, we can conclude that, at least in some cases, prosociality has a greater effect on moral character than does deception. 
Third, our findings offer insight into lay beliefs about universal moral values. We conceptualize prosocial lying not only as a conflict between honesty and benevolence, but more broadly as a conflict between justice and care. Prosocial lying reflects the violation of an ethical rule in order to care for another person. Providing care and avoiding harm towards others is a fundamental human tendency. Our findings demonstrate that care is, at least sometimes, more important than justice for moral character judgments. Importantly, our work illustrates the importance of studying conflicting moral rules (e.g. Broeders, van den Bos, Müller \& Ham, 2011).

Our study of justice and care also extends our understanding of deontological and utilitarian principles. Deontological philosophers argue that lying is immoral because it violates the sacred value of the right to truth (Kant, 1785). Utilitarians argue that the ethicality of lying depends upon its consequences (e.g. Martin Luther, cited in Bok, 1978; Bentham, 1843). Our findings support elements of both schools of thought. When lies are inconsequential, individuals do penalize liars for violating the principle of honesty. However, when lies help others the utilitarian consideration of consequences outweighs the deontological prohibition of deception. These findings reflect the ambivalence that we have for deception and quite possibly, many other moral violations. Perhaps our true moral compass reflects both deontological and utilitarian values.

Our work also contributes to the literature on moral dilemmas. In our investigation, we created a framework to explore a common type of ethical dilemma. Although prior research on ethical dilemmas and moral reasoning has substantially expanded our understanding of ethical decision-making, most of this work has studied extreme circumstances. For example, scholars use paradigms such as the trolley problem to study the dilemma of killing one person to save 
many (Broeders, van den Bos, Müller \& Ham, 2011; Greene, Nystrom, Engell, Darley, \& Cohen, 2004; Moore, Clark, \& Kane, 2008), and the Heinz dilemma to study the dilemma of stealing an expensive drug to save a life (Kohlberg, 1981). Our investigation extends our understanding of moral judgment by exploring conflicting moral principles in a context that pervades our everyday lives.

\section{Limitations and future directions}

Future work is needed to understand judgments of the full range of deceptive behaviors. In our studies, the intentions associated with lying were clear. In many settings, however, a liar's intentions are ambiguous. In addition to benefiting others, many prosocial lies also benefit the deceiver. For example, when a colleague asks if you enjoyed her talk, the prosocial lie ("It was great!') may benefit both the colleague (causing her to feel better) and the deceiver (avoiding a protracted discussion about the fatal flaws in the research). That is, a single act of deception may be both prosocial and self-serving. Future research should examine how individuals judge lies that have mixed or uncertain motives.

Future work should also explore how prosocial lying influences a broader set of perceptions and behaviors. For example, a substantial body of research suggests that deception harms trust (e.g. Boles, Croson \& Murninghan, 2000; Schweitzer, Hershey, \& Bradlow, 2006), but trust scholars have primarily investigated the consequences of selfish lies. Recent studies suggest that the relationship between deception and trust depends on the extent to which the liar's motives are believed to be prosocial (Levine \& Schweitzer, 2013; Wang \& Murighan, 2013). More research is needed to understand when prosocial lies, and ethical violations broadly, can increase trust and cooperation. 
Prosocial lying may also signal negative character traits. For example, prosocial lying may harm perceptions of moral traits other than benevolence and honesty, such as courage (Walker \& Hennig, 2004; Uhlmann, Zhu, \& Tannenbaum, 2013). If individuals consider prosocial lying to be cowardly, prosocial lying may decrease, rather than increase, perceptions of moral character. Prosocial lying may also have negative effects over time, as the signal value of benevolence weakens and the liar becomes less credible.

More broadly, we call for future research to expand our understanding of conflicts between moral principles. A substantial literature has explored characteristics of ethical decisionmaking when the ethical choice is clear (e.g., Mazar et al., 2008; Tenbrunsel, 1998; Boles, Croson, \& Murnighan, 2000); and a large literature has explored conflicts between deontological and utilitarian principles (e.g. Greene et al., 2004; Moore et al., 2008). However, scholars have largely overlooked behaviors that signal competing moral values (for exceptions, see Gino \& Pierce, 2009; Gino \& Pierce, 2010).

Ethicists and psychologists have argued that morality reflects a set of values, such as honesty, benevolence, restraint, and loyalty (e.g. Leach et al., 2007; Brambilla, Rusconi, Sacchi, \& Cherubini, 2011; Wojciszke, Bazinska, \& Jaworski, 1998; Reeder \& Spores, 1983; Noddings, 1984; Walker \& Hennig, 2004; Blasi, 1984; Aquino \& Reed, 2002) and that these values reflect different moral foundations, such as justice, care, purity, and authority (e.g. Haidt \& Graham, 2007). We investigate the conflict between justice and care, but important work remains with respect to understanding how individuals resolve — and judge others who resolve — conflicts between other principles, such as fairness and mercy (Kidder, 1995; Wiltermuth \& Flynn, 2012; Flynn \& Wiltermuth, 2010), and harm versus purity (e.g. Uhlmann \& Zhu, 2013). We argue that 
the study of conflicting moral principles represents a substantial challenge for ethical decisionmaking scholars.

\section{Conclusion}

Scholars, managers, and parents routinely extoll the virtues of honesty and warn of the dire consequences of deception. Deception, however, is not only pervasive but also employed by some of the same people who enjoin others to avoid its' use. In this work, we disentangle deception from intentions and outcomes. We investigate prosocial lies, lies told to benefit others, and find that prosocial lies are often judged to be more moral than honesty.

Prosocial lies represent a conflict between two moral foundations: justice and care. We call for future work to explore how individuals resolve conflicts between moral principles. 


\section{Acknowledgments}

The authors thank Katherine Milkman, Deborah Small, and Uri Simonsohn for their feedback and advice. We thank the Wharton Behavioral Laboratory and the Wharton Risk Center Ackoff Doctoral Student Fellowship for support. 


\section{References}

Alicke, M. D. (1992). Culpable causation. Journal of Personality and Social Psychology, 63(3), 368.

Ames, D. L., \& Fiske, S. T. (2013). Intentional Harms Are Worse, Even When They're Not. Psychological Science, 24(9), 1755-1762.

Aquino, K., \& Reed II, A. (2002). The self-importance of moral identity. Journal of Personality and Social Psychology, 83(6), 1423.

Barnes, MA, Claire. "Should Split Parents Ever Lie to Their Children?." The Huffington Post. TheHuffingtonPost.com, 2 Apr. 2013. Web. 11 Dec. 2013. $<$ http://www.huffingtonpost.com/claire-n-barnes-ma/should-split-parentsever_b_2964221.html>.

Bok, S. (1978). Lying: Moral choices in public and private life. New York, NY: Pantheon.

Bentham, J. (1843/1948). An introduction to the principles of morals and legislation. Oxford, UK: Basil Blackwell. (Original work published 1843).

Boles, T. L., Croson, R. T., \& Murnighan, J. K. (2000). Deception and retribution in repeated ultimatum bargaining. Organizational behavior and human decision processes, 83(2), 235-259.

Blasi, A. (1984). Moral identity: Its role in moral functioning. In W. Kurtines \& J. Gewirtz (Eds.), Morality, moral behavior and moral development (pp. 128-139). New York: Wiley.

Brambilla, M., Rusconi, P., Sacchi, S., \& Cherubini, P. (2011). Looking for honesty: The primary role of morality (vs. sociability and competence) in information 
gathering. European Journal of Social Psychology, 41(2), 135-143.

Brambilla, M., Sacchi, S., Rusconi, P., Cherubini, P., \& Yzerbyt, V. Y. (2012). You want to give a good impression? Be honest! Moral traits dominate group impression formation. British Journal of Social Psychology, 51(1), 149-166.

Broeders, R., van den Bos, K., Müller, P. A., \& Ham, J. (2011). Should I save or should I not kill? How people solve moral dilemmas depends on which rule is most accessible. Journal of Experimental Social Psychology, 47(5), 923-934.

Brown, P., \& Levinson, S. (1987). Politeness: Some universals in language usage. Cambridge, England: Cambridge University Press.

Cohen, T. R., Gunia, B. C., Kim-Jun, S. Y., \& Murnighan, J. K. (2009). Do groups lie more than individuals? Honesty and deception as a function of strategic self-interest. Journal of Experimental Social Psychology, 45(6), 1321-1324.

Critcher, C. R., Inbar, Y., \& Pizarro, D. A. (2013). How quick decisions illuminate moral character. Social Psychological and Personality Science, 4(3), 308-315

Craig, K. D. (2009). The social communication model of pain. Canadian Psychology/ Psychologie canadienne, 50(1), 22.

Croson, R., Boles, T., \& Murnighan, J. K. (2003). Cheap talk in bargaining experiments: Lying and threats in ultimatum games. Journal of Economic Behavior \& Organization, 51(2), 143-159.

Darley, J. M., \& Pittman, T. S. (2003). The psychology of compensatory and retributive justice. Personality and Social Psychology Review, 7(4), 324-336.

DePaulo, B. M., \& Kashy, D. A. (1998). Everyday lies in close and casual relationships. Journal of Personality and Social Psychology, 74(1), 63-79. 
DePaulo, B. M., Kashy, D. A., Kirkendol, S. E., Wyer, M. M., \& Epstein, J. A. (1996). Lying in everyday life. Journal of Personality and Social Psychology, 70(5), 979-995.

DePaulo, B. M., \& Bell, K. L. (1996). Truth and investment: lies are told to those who care. Journal of Personality and Social Psychology, 71(4), 703.

De Waal, F. B. (2008). Putting the altruism back into altruism: The evolution of empathy. Annual Review of Psychology, 59, 279-300.

Ditto, P. H., Pizarro, D. A., \& Tannenbaum, D. (2009). Motivated moral reasoning. Psychology of Learning and Motivation, 50, 307-338.

Dreber, A., \& Johannesson, M. (2008). Gender differences in deception. Economics Letters, 99(1), 197-199.

Erat, S., \& Gneezy, U. (2012). White lies. Management Science, 58(4), 723-733.

Flynn, F. J. \& Wiltermuth, S. S. (2010). Who's with me? False consensus, social networks, and ethical decision making in organizations. Academy of Management Journal, 53(5), 10741089.

Gaspar, J. P., \& Schweitzer, M. E. (2013). The Emotion Deception Model: A Review of Deception in Negotiation and the Role of Emotion in Deception. Negotiation and Conflict Management Research, 6(3), 160-179.

Gilligan, C. (1982). In a different voice: Psychological theory and women's development (Vol. 326). Harvard University Press.

Gino, F., \& Pierce, L. (2009). Dishonesty in the name of equity. Psychological Science, 20(9), 1153-1160.

Gino, F., \& Pierce, L. (2010). Lying to level the playing field: Why people may dishonestly help or hurt others to create equity. Journal of Business Ethics, 95(1), 89-103. 
Gneezy, U. (2005). Deception: The role of consequences. The American Economic Review, 95(1), 384-394.

Goffman, E. (1967). Interaction ritual: Essays on face-to-face behavior. Garden City, NJ: Anchor.

Graham, J., Haidt, J., \& Nosek, B. A. (2009). Liberals and conservatives rely on different sets of moral foundations. Journal of Personality and Social Psychology, 96(5), 1029.

Gray, K., Young, L., \& Waytz, A. (2012). Mind perception is the essence of morality. Psychological Inquiry, 23(2), 101-124.

Gray, K., Schein, C., \& Ward, A. F. (2014). The Myth of Harmless Wrongs in Moral Cognition: Automatic Dyadic Completion from Sin to Suffering. Journal of Experimental Psychology: General. Advance online publication. http://dx.doi.org/10.1037/a0036149

Greene, J. D., Nystrom, L. E., Engell, A. D., Darley, J. M., \& Cohen, J. D. (2004). The neural bases of cognitive conflict and control in moral judgment. Neuron, 44(2), 389-400.

Haidt, J., \& Graham, J. (2007). When morality opposes justice: Conservatives have moral intuitions that liberals may not recognize. Social Justice Research, 20(1), 98-116.

Iezzoni, L. I., Rao, S. R., DesRoches, C. M., Vogeli, C., \& Campbell, E. G. (2012). Survey shows that at least some physicians are not always open or honest with patients. Health Affairs, 31(2), 383-391.

Kant, I. (1785). Foundation of the metaphysics of morals. Beck LW, translator. Indianapolis: Bobbs-Merrill; 1959.

Kashy, D. A., \& DePaulo, B. M. (1996). Who lies? Journal of Personality and Social Psychology, 70(5), 1037. 
Kidder, R.M. (1995). How good people make tough choices: Resolving the dilemmas of ethical living. New York: Fireside.

Kohlberg, L. (1969). Stage and sequence: The cognitive-developmental approach to socialization (pp. 347-480). New York: Rand McNally.

Knobe, J. (2004). Intention, intentional action and moral considerations. Analysis, 64(282), 181187.

Koning, L., Steinel, W., Beest, I. V., \& van Dijk, E. (2011). Power and deception in ultimatum bargaining. Organizational Behavior and Human Decision Processes,115(1), 35-42.

Lapsley, D. K., \& Lasky, B. (2001). Prototypic moral character. Identity: An International Journal of Theory and Research, 1(4), 345-363.

Leach, C. W., Ellemers, N., \& Barreto, M. (2007). Group virtue: the importance of morality (vs. competence and sociability) in the positive evaluation of in-groups. Journal of Personality and Social Psychology, 93(2), 234.

Levine, E. E., \& Schweitzer, M. E., (2013). Prosocial lies: When deception breeds trust. Working Paper. University of Pennsylvania.

Mazar, N., Amir, O., \& Ariely, D. (2008). The dishonesty of honest people: A theory of selfconcept maintenance. Journal of Marketing Research, 45(6), 633-644.

Mead, N. L., Baumeister, R. F., Gino, F., Schweitzer, M. E., \& Ariely, D. (2009). Too tired to tell the truth: Self-control resource depletion and dishonesty. Journal of experimental social psychology, 45(3), 594-597.

Moore, A. B., Clark, B. A., \& Kane, M. J. (2008). Who shalt not kill? Individual differences in working memory capacity, executive control, and moral judgment. Psychological Science, 19(6), 549-557. 
Noddings, N. (1984). Caring: A feminine approach to ethics and moral education. Berkeley, CA: University of California Press.

Palmieri, J. J., \& Stern, T. A. (2009). Lies in the doctor-patient relationship. Primary care companion to the Journal of clinical psychiatry, 11(4), 163.

Park, Alice. "White Coats, White Lies: How Honest Is Your Doctor." Time Magazine, 10 Dec. 2011. Web. 11 Dec. 2013. <http://healthland.time.com/2012/02/09/white-coats-whitelies-how-honest-is-your-doctor/>.

Pizarro, D. A., Uhlmann, E., \& Bloom, P. (2003). Causal deviance and the attribution of moral responsibility. Journal of Experimental Social Psychology, 39(6), 653-660.

Reeder, G. D. (2009). Mindreading: Judgments about intentionality and motives in dispositional inference. Psychological Inquiry, 20(1), 1-18.

Reeder, G. D., \& Spores, J. M. (1983). The attribution of morality. Journal of Personality and Social Psychology, 44(4), 736.

Rosenberg, S., Nelson, C., \& Vivekananthan, P. S. (1968). A multidimensional approach to the structure of personality impressions. Journal of Personality and Social Psychology, 9(4), 283.

Rai, T. S., \& Fiske, A. P. (2011). Moral psychology is relationship regulation: moral motives for unity, hierarchy, equality, and proportionality. Psychological Review, 118(1), 57.

Ruedy, N., Moore, C., Gino, F., \& Schweitzer, M. (2013). The Cheater's High: The Unexpected Affective Benefits of Unethical Behavior. Journal of Personality and Social Psychology, 105(4), 531-548.

Schweitzer, M. E., \& Croson, R. (1999). Curtailing deception: The impact of direct questions on lies and omissions. International Journal of Conflict Management,10(3), 225-248. 
Schweitzer, M. E., DeChurch, L. A., \& Gibson, D. E. (2005). Conflict Frames and the Use of Deception: Are Competitive Negotiators Less Ethical? Journal of Applied Social Psychology, 35(10), 2123-2149.

Schweitzer, M. E., Hershey, J. C., \& Bradlow, E. T. (2006). Promises and lies: Restoring violated trust. Organizational Behavior and Human Decision Processes, 101(1), 1-19.

Shalvi, S. (2012). Dishonestly increasing the likelihood of winning. Judgment and Decision Making, 7(3), 292-303.

Shalvi, S., Dana, J., Handgraaf, M. J., \& De Dreu, C. K. (2011). Justified ethicality: Observing desired counterfactuals modifies ethical perceptions and behavior. Organizational Behavior and Human Decision Processes, 115(2), 181-190.

Shu, L. L., Mazar, N., Gino, F., Ariely, D., \& Bazerman, M. H. (2012). Signing at the beginning makes ethics salient and decreases dishonest self-reports in comparison to signing at the end. Proceedings of the National Academy of Sciences, 109(38), 15197-15200.

Simmons, J. P., Nelson, L. D., \& Simonsohn, U. (2011). False-positive psychology: Undisclosed flexibility in data collection and analysis allows presenting anything as significant. Psychological Science, 22(11), 1359-1366.

Steinel, W., \& De Dreu, C. K. (2004). Social motives and strategic misrepresentation in social decision making. Journal of Personality and Social Psychology, 86(3), 419.

Tannenbaum, D., Uhlmann, E. L., \& Diermeier, D. (2011). Moral signals, public outrage, and immaterial harms. Journal of Experimental Social Psychology, 47(6), 1249-1254.

Tenbrunsel, A. E. (1998). Misrepresentation and expectations of misrepresentation in an ethical dilemma: The role of incentives and temptation. Academy of Management Journal, 41(3), 330-339. 
Tyler, J. M., Feldman, R. S., \& Reichert, A. (2006). The price of deceptive behavior: Disliking and lying to people who lie to us. Journal of Experimental Social Psychology, 42(1), 6977.

Turiel, E. (1983). The development of social knowledge: Morality and convention. Cambridge University Press.

Turiel, E., Hildebrandt, C., \& Wainryb, C. (1991). Judging social issues: Difficulties, inconsistencies and consistencies: I. Monographs of the society for research in child development.

Uhlmann, E. L., Zhu, L. L., \& Tannenbaum, D. (2013). When it takes a bad person to do the right thing. Cognition, 126, 326-334.

Uhlmann, E. L., \& Zhu, L. (2013). Acts, persons, and intuitions: Person-centered cues and gut reactions to harmless transgressions. Social Psychological and Personality Science.

Young, L., \& Saxe, R. (2008). The neural basis of belief encoding and integration in moral judgment. Neuroimage, 40(4), 1912-1920.

Yuill, N., \& Perner, J. (1988). Intentionality and knowledge in children's judgments of actor's responsibility and recipient's emotional reaction. Developmental Psychology, 24, 358365.

Walker, L. J., \& Hennig, K. H. (2004). Differing conceptions of moral exemplarity: Just, brave, and caring. Journal of Personality and Social Psychology, 86, 629-647.

Wang, L. \& Murnighan, J.K. (2013). Trust, White Lies, and Harsh Truths. Working Paper. City University of Hong Kong.

Wiltermuth, S., \& Flynn, F. (2012). Power, Moral Clarity, and Punishment in the Workplace. Academy of Management Journal, 56, 1002-1023. 
Wojciszke, B. (2005). Morality and competence in person-and self-perception. European Review of Social Psychology, 16(1), 155-188.

Wojciszke, B., Bazinska, R., \& Jaworski, M. (1998). On the dominance of moral categories in impression formation. Personality and Social Psychology Bulletin, 24(12), 1251-1263. 


\section{TABLES}

\section{Table 1}

Payoffs used in each study

\begin{tabular}{lcrcc} 
& Type of Lie & & $\begin{array}{c}\text { Payoffs associated } \\
\text { with Truth }\end{array}$ & $\begin{array}{c}\text { Payoffs associated } \\
\text { with Lie }\end{array}$ \\
\cline { 2 - 5 } Study 1 & Altruistic Lie & Sender & $\$ 2.00$ & $\$ 1.75$ \\
& & Receiver & $\$ 0.00$ & $\$ 1.00$ \\
\hline Study 2 & Altruistic Lie & Sender & $\$ 2.00$ & $\$ 1.75$ \\
& & Receiver & $\$ 0.00$ & $\$ 1.00$ \\
& Selfish Lie & Sender & $\$ 1.75$ & $\$ 2.00$ \\
& & Receiver & $\$ 1.00$ & $\$ 0.00$ \\
\hline Study 3 & Control Lie & Sender & $\$ 2.00$ & \\
& & Receiver & $\$ 0.00$ & $\$ 2.00$ \\
& Self-Sacrificial Lie & Sender & $\$ 2.00$ & $\$ 1.00$ \\
& & Receiver & $\$ 0.00$ & $\$ 0.00$ \\
& Prosocial Lie & Sender & $\$ 2.00$ & $\$ 2.00$ \\
& & Receiver & $\$ 0.00$ & $\$ 1.00$ \\
& Altruistic Lie & Sender & $\$ 2.00$ & $\$ 1.75$ \\
& & Receiver & $\$ 0.00$ & $\$ 1.00$
\end{tabular}

Note. In Study 2, the values displayed correspond to the intended outcome, but not necessarily the realized outcome, associated with each choice. In Study 2, the computer overrode the Sender's choice some of the time, such that the computer sent an honest message in place of a dishonest message, or a dishonest message in place of an honest message. 
Table 2

Scale Statistics in Studies 1, 2, and 3

\section{Study 1}

\begin{tabular}{lrrr} 
Scale & $\mathrm{M}(\mathrm{SD})$ & 1 & 2 \\
\hline \hline 1. Moral Character & $4.67(1.16)$ & & \\
2. Benevolence & $4.67(1.68)$ & $0.77^{*}$ & \\
3. Honesty & $4.29(1.51)$ & $0.24^{*}$ & 0.10
\end{tabular}

Study 2

\begin{tabular}{lrrr} 
Scale & $\mathrm{M}(\mathrm{SD})$ & 1 & 2 \\
\hline \hline 1. Moral Character & $4.47(1.49)$ & & \\
2. Benevolence & $4.44(1.66)$ & $0.89^{*}$ & \\
3. Honesty & $4.34(1.87)$ & $0.72^{*}$ & $0.66^{*}$
\end{tabular}

Study 3

\begin{tabular}{lrrr} 
Scale & $\mathrm{M}(\mathrm{SD})$ & 1 & 2 \\
\hline \hline 1. Moral Character & $4.27(1.37)$ & & \\
2. Benevolence & $3.95(1.32)$ & $0.83^{*}$ & \\
3. Honesty & $4.19(1.67)$ & $0.64 *$ & $0.48^{*}$
\end{tabular}

Note. ${ }^{*} p<.01$. 
Table 3

Summary of Results (Study 3)

\begin{tabular}{|c|c|c|c|}
\hline \multirow[b]{2}{*}{ Type of Lie } & \multicolumn{2}{|c|}{ Consequences of Lying } & \multirow{2}{*}{$\begin{array}{l}\text { Perceptions of } \\
\text { moral character }\end{array}$} \\
\hline & To Sender & To Receiver & \\
\hline Prosocial Lie & No consequences & Helps & Increase \\
\hline
\end{tabular}

$\begin{array}{llll}\text { Altruistic Lie } & \text { Harms } & \text { Helps } & \text { Increase } \\ \text { Self-Sacrificial Lie } & \text { Harms } & \text { No consequences } & \text { Decrease } \\ \begin{array}{l}\text { Inconsequential Lie } \\ \text { (Control) }\end{array} & \text { No consequences } & \text { No consequences } & \text { Decrease }\end{array}$




\section{FIGURES}

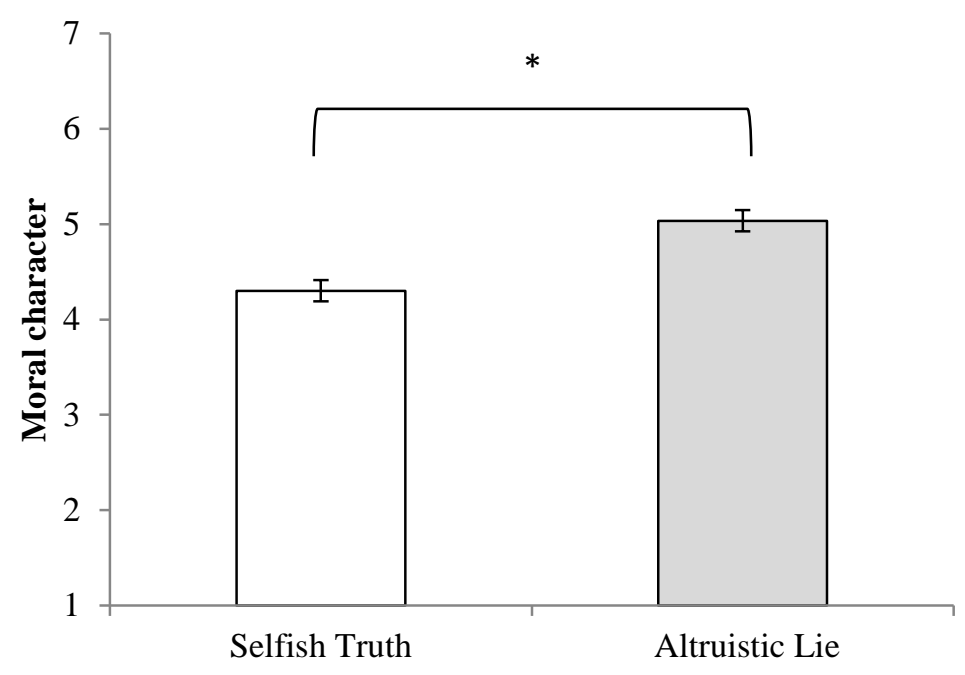

Figure 1: Moral character judgments in Study 1. Error bars represent \pm 1 SE. $* p<.05$. 


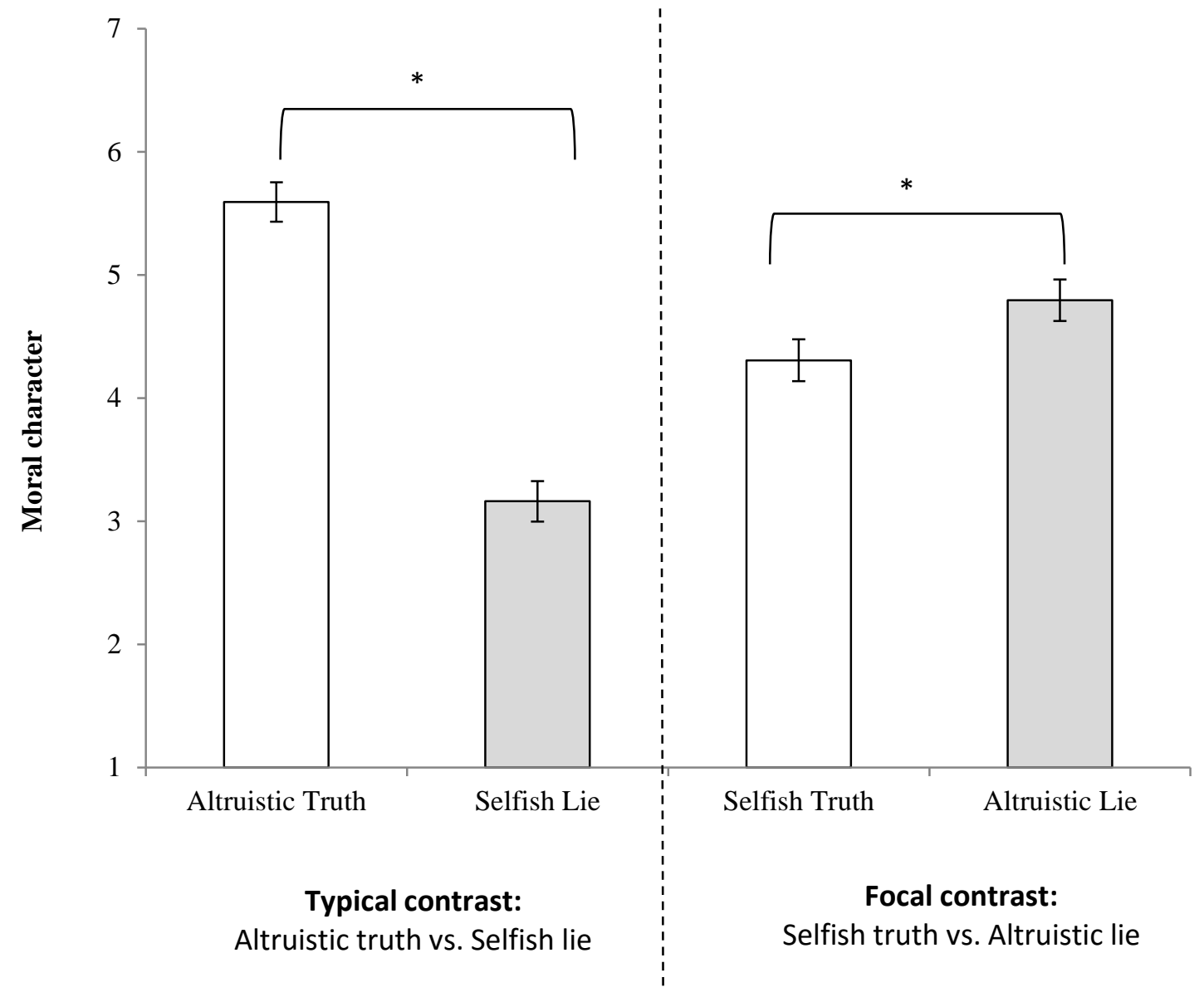

Figure 2: Moral character judgments in Study 2. Error bars represent \pm 1 SE. $* p<.05$. 


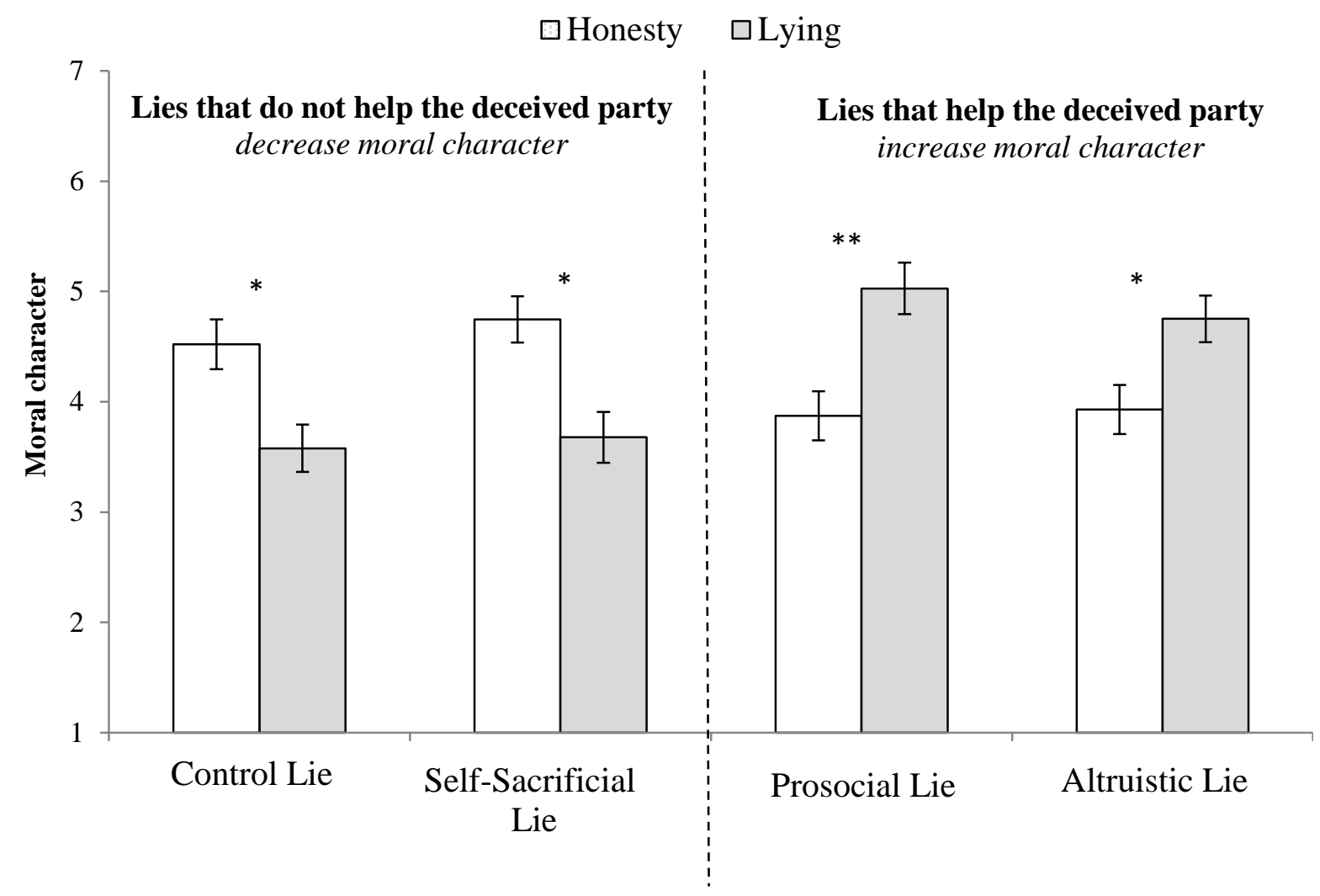

Figure 3: Moral character judgments in Study 3. Error bars represent \pm 1 SE. * $p<.01$, ** $p<$ .001 . 


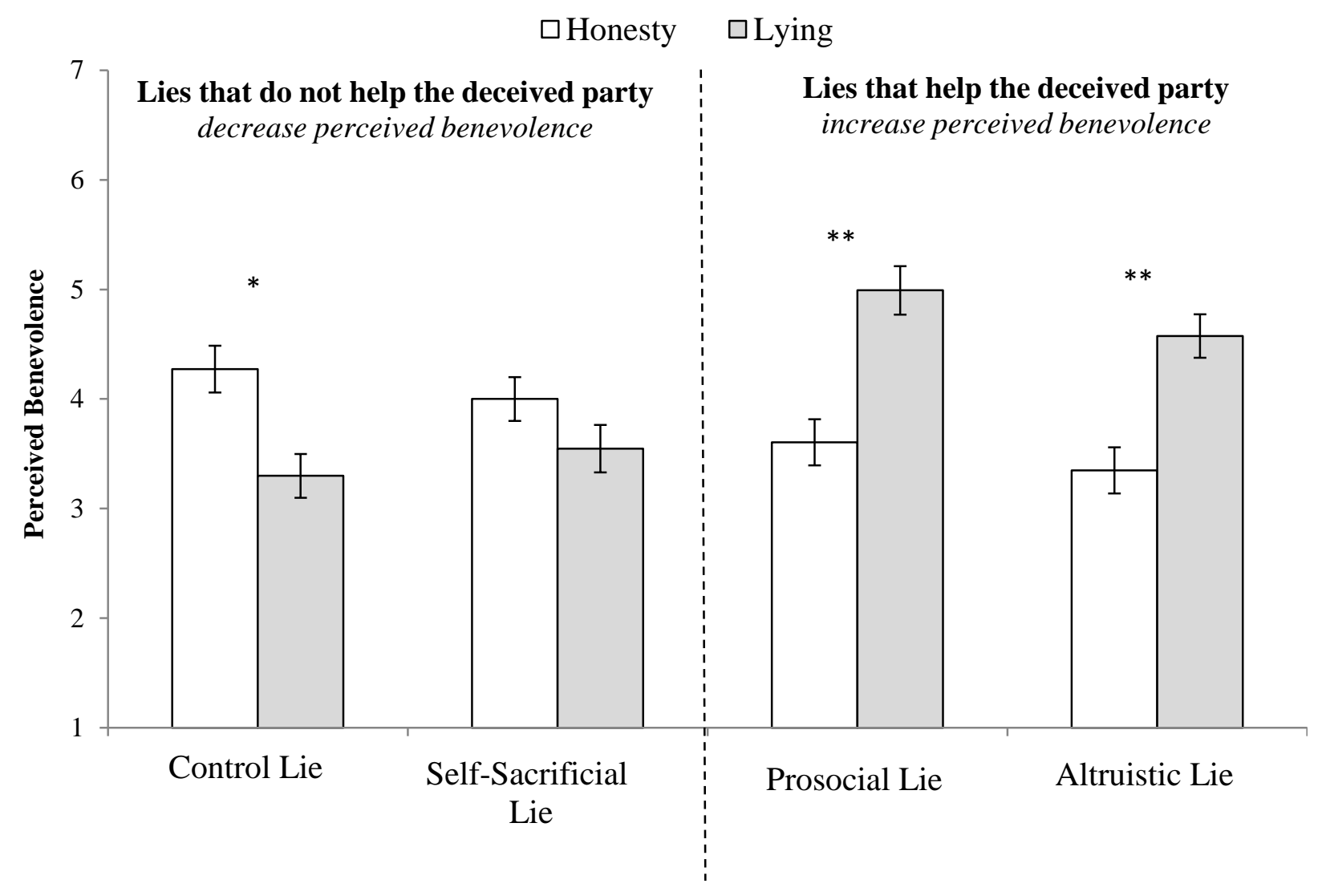

Figure 4: Perceived benevolence in Study 3. Error bars represent \pm 1 SE. $* p<.01, * * p<.001$. 


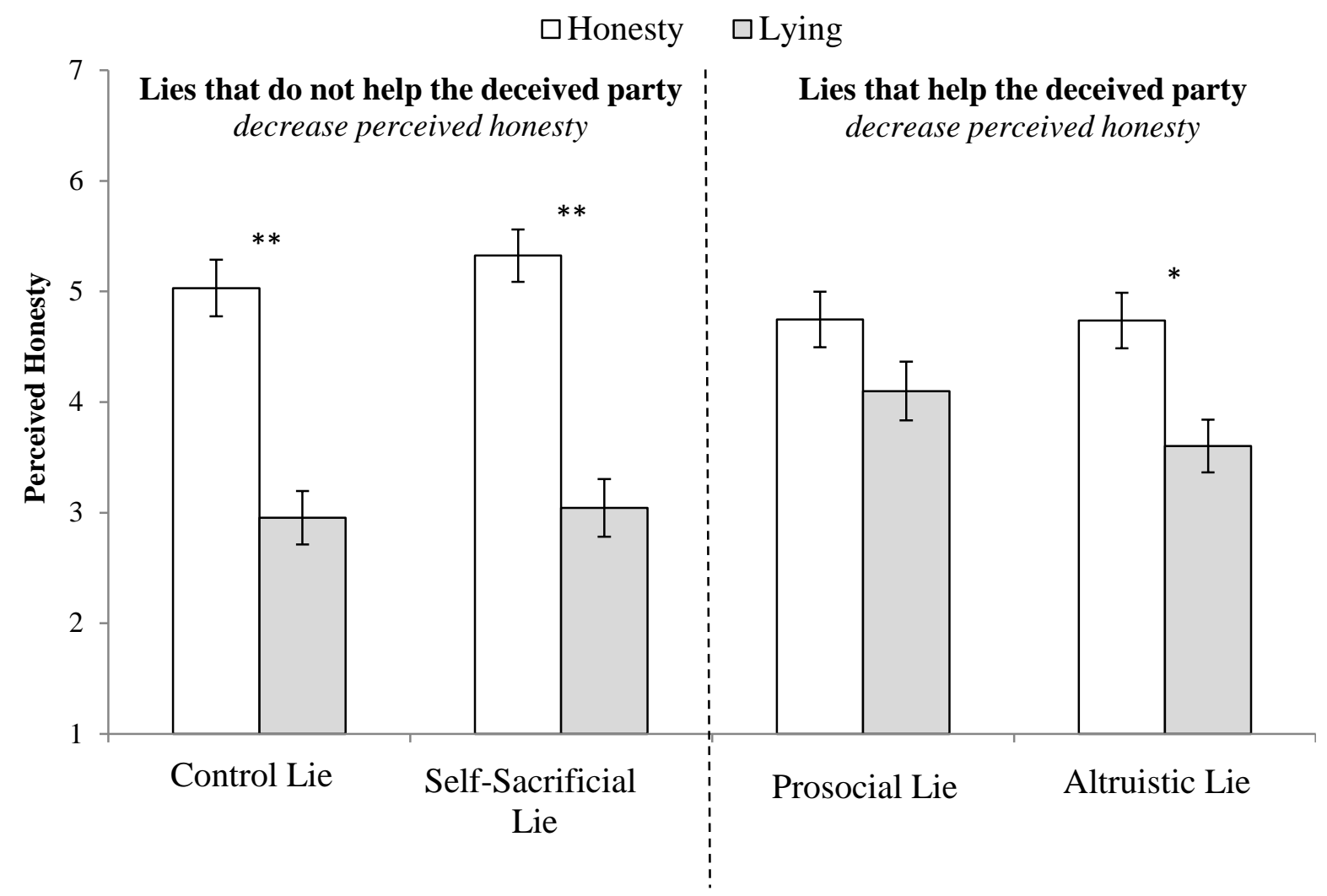

Figure 5: Perceived honesty in Study 3. Error bars represent \pm 1 SE. $* p<.01, * * p<.001$. 